\title{
miR-146b Inhibits Glucose Consumption by Targeting IRS1 Gene in Porcine Primary Adipocytes
}

\author{
Yan-Ling Zhu ${ }^{\dagger}$, Ting Chen ${ }^{\dagger}$, Jia-Li Xiong, Di Wu, Qian-Yun Xi, Jun-Yi Luo ${ }^{\circledR}$, Jia-Jie Sun * \\ and Yong-Liang Zhang * \\ College of Animal Science, Guangdong Provincial Key Laboratory of Animal Nutrition Control, \\ South China Agricultural University, Guangzhou 510642, China; Kerryju27@163.com (Y.-L.Z.); \\ allinchen@scau.edu.cn (T.C.); XJL00LJX@163.com (J.-L.X.); diwu@huskers.unl.edu (D.W.); \\ xqy0228@163.com (Q.-Y.X.); luojunyi@scau.edu.cn (J.-Y.L.) \\ * Correspondence: jiajiesun@scau.edu.cn (J.-J.S.); zhangyl@scau.edu.cn (Y.-L.Z.); \\ Tel./Fax: +86-020-8528-5931 (Y.-L.Z.) \\ + These authors contributed equally to this work.
}

Received: 2 February 2018; Accepted: 27 February 2018; Published: 9 March 2018

\begin{abstract}
Adipose tissue plays an important role in energy metabolism. Adipose dysfunction is closely related to obesity and type II diabetes. Glucose uptake is the key step for fat synthesis in adipocyte. miRNAs have been proven to play a crucial role in adipocyte differentiation, adipogenesis and glucose homeostasis. In this paper, we firstly reported that miR-146b decreased glucose consumption by up-regulating miR-146b in a porcine primary adipocyte model, while the inhibitor of endogenous miR-146b rescued the reduction. Then, miR-146b was predicated to target IRS1 by bioinformatics analysis, and a dual-luciferase reporter assay validated this predication. Western blot analyses indicated both IRS1 and glucose transporter type 4 (GLUT4) were down-regulated by miR-146b overexpression. Our study demonstrated that miR-146b regulated glucose homeostasis in porcine primary pre-adipocyte by targeting IRS1, and provided new understandings on regulations of lipogenesis by miRNAs.
\end{abstract}

Keywords: miR-146b; glucose consumption; adipocyte; GLUT4; IRS1

\section{Introduction}

Adipose tissue is no longer considered merely as a storage depot but is also known to participate in immune and inflammation responses [1], blood pressure control [2], thyroid [3], reproductive functions [4], and to make considerable contribution to maintaining glucose homeostatic [5]. Serum glucose is taken up by adipocytes for lipogenesis, and it is a way to keep the concentration of blood glucose at a reasonable level [6-9]. Insulin is the key hormone in controlling blood glucose, preventing gluconeogenesis in the liver while promoting blood glucose uptake into muscles and adipose tissues via regulating the glucose transporter type 4 (GLUT4) trafficking from intracellular stores to the plasma membrane [10]. In adipose tissues, the absorbed glucose is converted into triglycerides through lipogenesis [11]. GLUT4 is the main glucose transporter in adipocytes, which is found from an intracellular store to the plasma membrane with the insulin trigger [12,13]. GLUT4 contributes a lot to maintain body glucose homeostasis. Both type II diabetes and insulin resistant mice show disruption of GLUT4 expression $[14,15]$. While GLUT4 is overexpressed, diabetes syndrome is ameliorated in the $d b / d b$ mouse model [16]. The presence of insulin in the extracellular fluids affects metabolic changes via a complicated method [17]. In basal cells, GLUT4 is sequestered in GLUT4 storage vesicles (GSVs) which contain the v-SNARE to form a complex for conducting the GLUT4 translocation to the cell plasma membrane [18]. Only approximately 5\% of the GSVs are found on the plasma membrane in the absence of insulin stimulation $[19,20]$. After insulin binds to the insulin receptor 
(IR), it promotes the autophosphorylation of a trio of regulatory loop tyrosine residues by activated tyrosine kinase [21]. It phosphorylates IR and leads to the recruitment and Tyr phosphorylation of the insulin receptor substrate (IRS) [10,22-24]. The Tyr-phosphorylated IRS1 activates a series of intracellular phosphorylation cascades in motion, resulting in GLUT4 translocation [25]. IRS1 serves as a docking site for the SH2 domain of PI3K, which activates PI3K and the subsequent phosphorylation of PDK1 and AKT [26]. AKT is activated and phosphorylated through dual Ser/Thr phosphorylation by PDK1 [27]. Activated AKT is attributable to GLUT4 trafficking to the plasma membrane [28-30]. Hence, IRS1 plays a significant role in glucose homeostasis in adipose tissues via affecting GLUT4 translocation in the IRS1/GLUT4 signaling pathway.

As a type of non-coding RNAs with approximately twenty-two nucleotides [31], microRNAs(miRNAs) have been involved in many biological processes through their post-transcriptional regulatory influences on genes or transcription factors [32]. Studies have shown that miRNAs are key regulators of the cell cycle [33], adipocyte differentiation [34,35], adipogenesis [36,37], cholesterol and lipid regulation [38,39], insulin signaling and glucose homeostasis [40]. Insulin resistance occurs when the insulin signaling pathway is impaired [10], and it is termed one of the most prevalent metabolic abnormalities [41], which causes obesity and type 2 diabetes (T2D) [10,42]. It has been shown that miRNAs are involved in the insulin signaling pathway [43]; miR-144 directly targets IRS1 in pancreatic islets isolated from T2D rats [44] and miR-628 benefits burn-induced skeletal muscle atrophy by targeting IRS1 [45]. IRS1 and GLUT4 in miR-155 KO mice adipocytes are found to be up-regulated [46].

In our previous study, miR-146a-5p was proved to target the insulin receptors(IR) and, thus, inhibited TNF $\alpha$-induced adipogenesis in porcine primary adipocytes [47]. The miR-146b was also found to be significantly up-regulated in porcine primary adipocytes after TNF $\alpha$ treatment, but the role of miR-146b remains unclear. In this study, we confirmed that miR-146b decreased glucose consumption by targeting IRS1 in porcine primary adipocytes involving adipogenesis.

\section{Results}

\section{1. miR-146b Inhibits Glucose Consumptionin}

Porcine primary adipocytes were cultured till the lipid droplets accumulated. miR-146b mimic/NC/ inhibitor/iNC were transfected into pre-adipocytes, and cells were collected at days 4, 6 and 8 post-induction. The expression levels of miR-146b were measured by RT-qPCR. The results showed that miRNA mimics significantly increased miR-146b levels, while inhibitors significantly decreased miR-146b expression compared with NC (Figure 1). On days 4, 6, 8 post-transfection, miR-146b mimic obviously reduced scavenging effects on glucose in porcine adipocytes compared with the $\mathrm{NC}$ group (Figure 2A,C,E), and this reduction was rescued by the transfection of miR-146b inhibitors (Figure 2B,D,F).
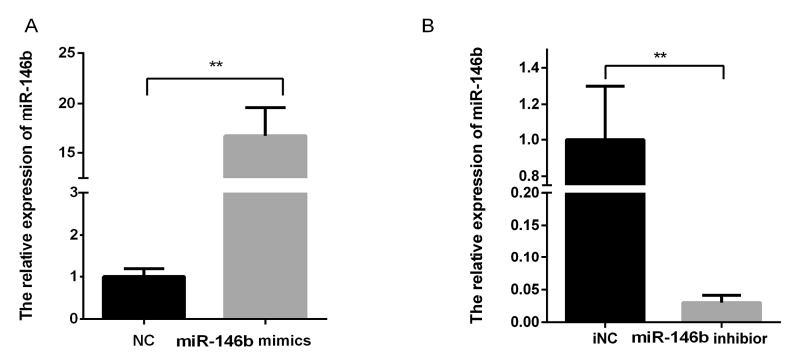

Figure 1. The miR-146b expression levels with transfection of miRNA mimics and inhibitor. Note: miR-146b mimics/NC/inhibitor/iNC were transfected into pre-adipocytes, and cells were collected on day 8 post-induction. After transfection and day 8 post-induction with miR-146b mimics and inhibitor, the expression levels of miR-146b were measured by a qPCR-based method. miRNA mimics (A) and inhibitors (B) significantly increased and decreased miR-146b levels compared with NC and iNC control, respectively, in adipocytes $\left(n=6,{ }^{* *} p<0.01\right)$. 
A

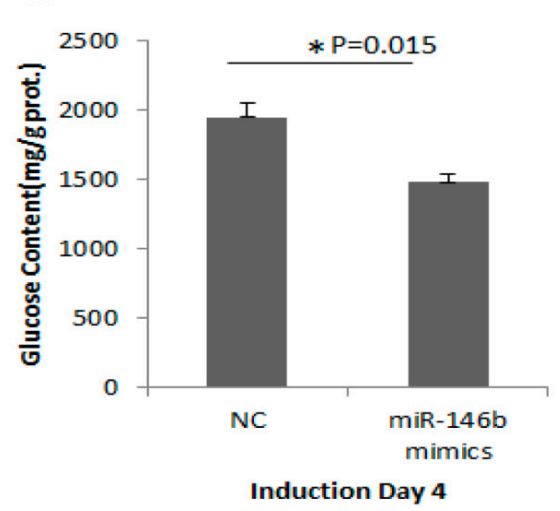

$\mathrm{C}$

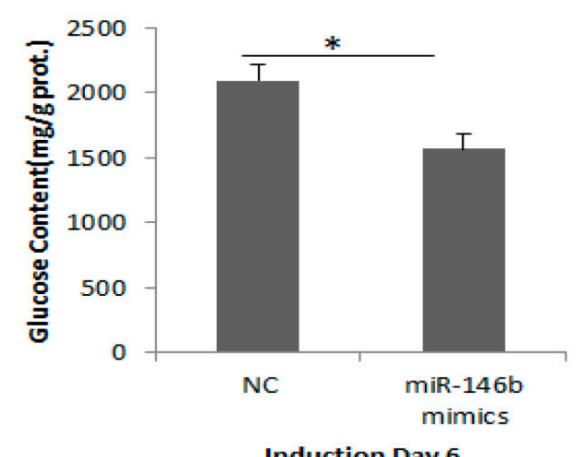

E

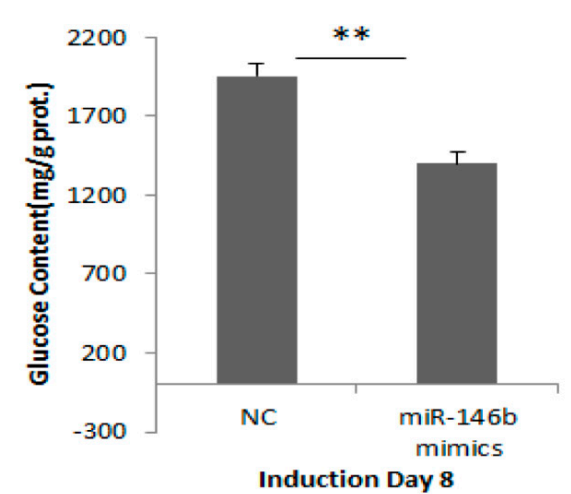

B

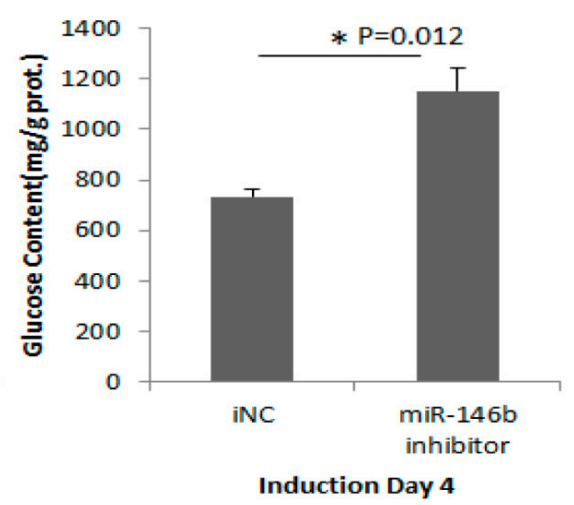

$\mathrm{D}$

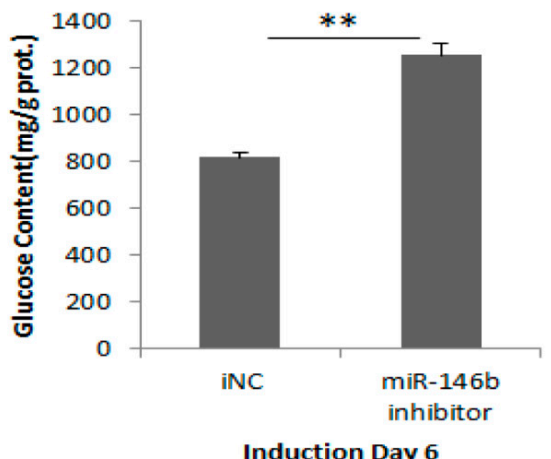

F

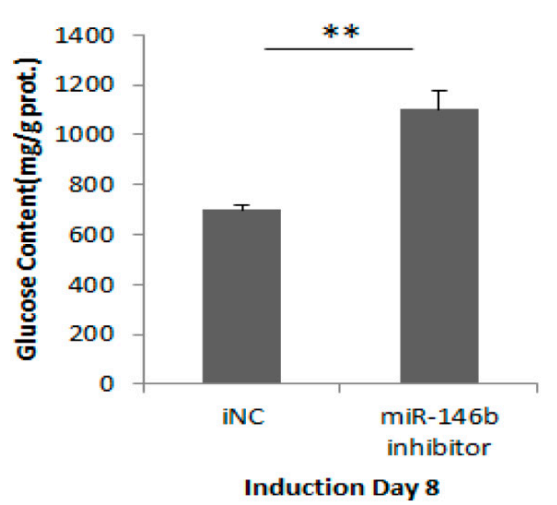

Figure 2. miR-146b inhibits the scavenging effects on glucose in porcine adipocytes. Note: Glucose consumption was determined after transfection of miR-146b mimics/NC or inhibitor/iNC. miR-146b mimics significantly reduced glucose clearance on day 4 (A); 6 (C) and 8 (E) respectively, while inhibitors exerted the opposite results $(\mathbf{B}, \mathbf{D}, \mathbf{F})$. Data were presented as mean $\pm \operatorname{SD}(n=6, * p<0.05$, ** $p<0.01)$.

\subsection{Target Prediction and Pathway Analysis}

Target prediction was carried out by the RNAhybrid software, and all the candidates of miR-146b were annotated in KEGG pathway analysis using the DAVID v6.7 online service (https: / / david.ncifcrf. gov/). The KEGG pathway analysis revealed that the predicted targets of the miR-146b were involved in ten pathways (Table 1), of which adipocytokine signaling pathway is relevant to glucose intake by adipocytes. The predicted targets included GLUT4 and IRS1 genes that were related to changes of glucose transport and consumption. Thus, we speculated that miR-146b may affect glucose uptake via these two molecules. 
Table 1. KEGG pathway analysis of candidates predicted by RNAhybrid software.

\begin{tabular}{ccc}
\hline Pathway Term & Genes & $p$-Value \\
\hline Adipocytokine signaling pathway & CPT1, FACS, IRS, AMPK, GLUT4, LEPR & $2.7 \times 10^{-3}$ \\
T cell receptor signaling pathway & CD4/8, CD3y, Rho, Cdb42, NFAT, Ras, ICOS & $3.2 \times 10^{-3}$ \\
Phagosome & MHCII, TLR4, Dynein, SRB1, TUBB, vATPase & $3.8 \times 10^{-3}$ \\
Focal Adhesion & $E C M$, ITGA, ITGB, RhoA, MLC, Caveolin, Vinculin & $4.8 \times 10^{-2}$ \\
Regulation of actin cytoskeleton & ITG, Ras, Rho, VCL, PI4P5K, MLC, Arp2/3, WAVEE & $1.8 \times 10^{-2}$ \\
Bacterial invasion of epithelial cells & WAVE, Arp2/3, RhoA, Vinculin, Caveollin & $2.0 \times 10^{-2}$ \\
AMPK signaling pathway & Ob-Rb, AMPK, GLUT4, IRS1, Rab, CPT1 & $2.2 \times 10^{-2}$ \\
FoxO signaling pathway & Smad4, AMPK, GLUT4, IRS, Ras, ATM & $3.5 \times 10^{-2}$ \\
Neurotrophin Signaling Pathway & NT4, IRS1, Ras, RhoA, p53 & $7.7 \times 10^{-2}$ \\
\hline
\end{tabular}

\section{3. miR-146b Repressed GLUT4 and IRS1 Protein Expression}

To explore whether miR-146b could affect the GLUT4 and IRS1 protein expression levels, we transfected miR-146b mimics, NC, inhibitor and iNC into porcine pre-adipocytes and measured GLUT4 and IRS1 protein expression at day 8 post-transfection. Western blot analysis showed that miR-146b mimics significantly suppressed both GLUT4 and IRS1 protein expressions, while the inhibitor rescued the decrease (Figure 3A,B). In addition, previous papers reported that in adipocytes, glucose uptake is dependent on the translocation of GLUT4 from intracellular storage compartments to the plasma membrane (PM) [48,49]. Our results demonstrated that miR-146b reduced GLUT4 translocation to the PM (Figure 3C), which might clarify that miR-146b plays a role in reducing glucose consumption.

$$
\text { A }
$$
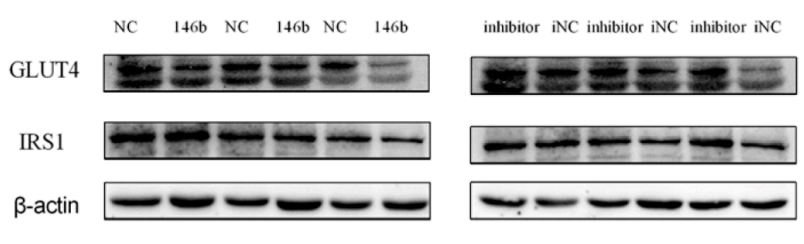

B
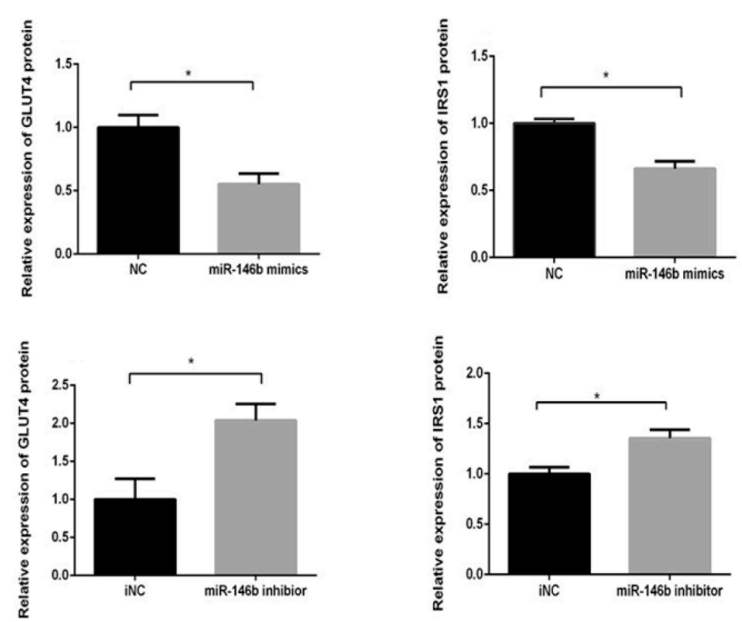

C

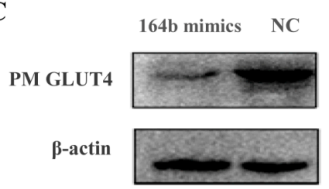

Figure 3. miR-146b repressed GLUT4 and IRS1 protein expression. (A) GLUT4 and IRS1protein was down-regulated after miR-146b transfection and this reduction was rescued by the miR-146b inhibitor; (B) Data are presented as mean $\pm \mathrm{SD}\left({ }^{*} p<0.05, n=6\right)$; (C) Plasma membrane (PM) proteins were extracted from the differentiated cells and miR-146b mimics reduced the GLUT4 protein expression of the PM. 


\subsection{Identification of miR-146b Targets by Luciferase Reporter Assay}

To validate the targeted relationship between miR-146b and 3'UTR of porcine GLUT4 (Figure 4A) and IRS1 (Figure 5A) genes, the wild-type (pGLO-3'UTR), mutant and deletion (pGLO-3'UTR-mut and pGLO-3'UTR-del) plasmid (Figures 4B and 5B) were co-transfected with a miR-146b mimic into Hela cells. At $48 \mathrm{~h}$ post-transfection, the luciferase activity of each group was assayed, and for target IRS1 gene, the miR-146b mimics group showed lower luciferase activity when compared with the NC group (Figures $4 \mathrm{C}$ and $5 \mathrm{C}$ ). The reduction was rescued both by mutation and deletion of the seed sequence. Intriguingly, miR-146b was found to be highly similar between pigs and humans (Figure 6A). The 3'UTR of pigs or human IRS1 mRNA contains a binding site which perfectly matched the seed region of miR-146b (Figure 6B).

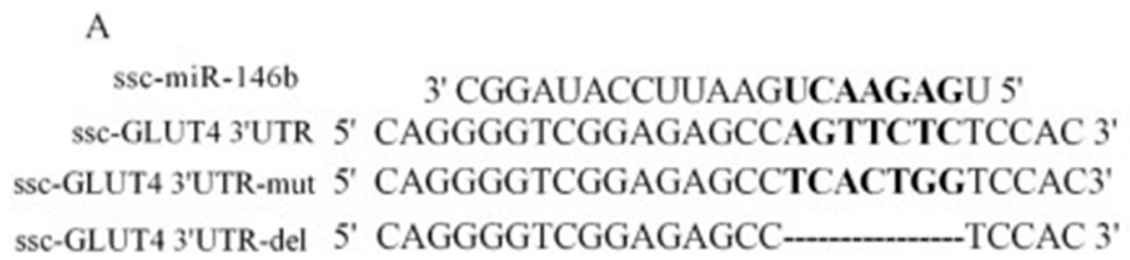

B

\begin{tabular}{|c|c|c|}
\hline Luciferase & GLUT4 3'UTR & pGLO-GLUT4 3'UTR \\
\hline Luciferase & GLUT4 3'UTR-mut & pGLO-GLUT4 3'UTR-mut \\
\hline Luciferase & GLUT4 3'UTR-del & -pGLO-GLUT4 3'UTR-del \\
\hline
\end{tabular}

C

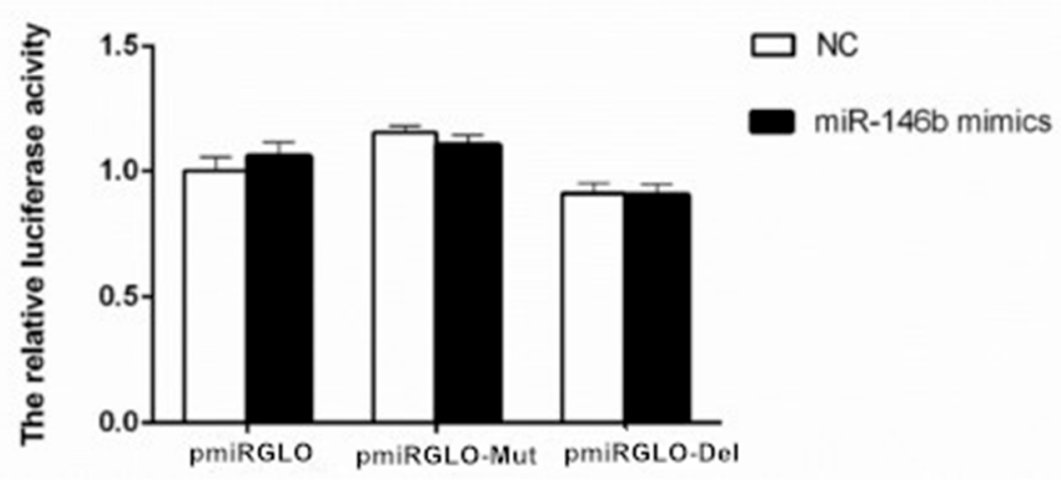

Figure 4. ssc-miR-146b not directly targets porcine GLUT4 by luciferase reporter assay. (A) Three $3^{\prime}$-UTR sequences containing normal, mutagenic, and deleted binding sites were inserted downstream of the luciferase reporter. Seven nucleotides of GLUT4 3'-UTR were mutated and deleted to disrupt the binding with miR-146b seed regions; (B) Schematic diagram showing dual-luciferase reporter constructs of pig GLUT4 3'-UTR with putative miR-146b binding site; (C) Constructed vectors were transfected into Hela cells with miR-146 mimics or NC. The luciferase assay results revealed no significant differences betweenmiR-146b mimics and NC transfected with vectors containing normal GLUT4 3'-UTR, mutant GLUT4 3'-UTR and the deletion $(n=8)$. 


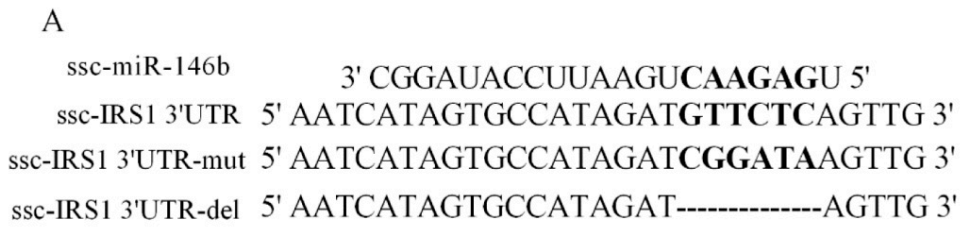

B

\begin{tabular}{|c|c|c|}
\hline Luciferase & IRS1 3'UTR & - pGLO-IRS1 3'UTR \\
\hline Luciferase & IRS1 3'UTR-mut & pGLO-IRS1 3'UTR-m \\
\hline Luciferase & IRS1 3'UTR-del & pGLO-IRS1 3'UTR-del \\
\hline
\end{tabular}

C

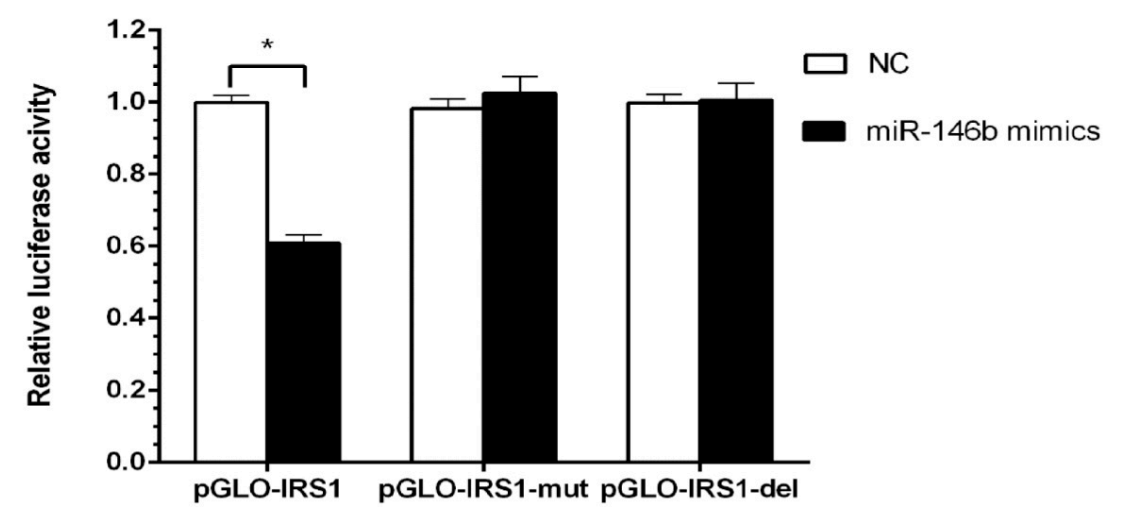

Figure 5. Verification of ssc-miR-146 direct targets of porcine IRS1 by luciferase reporter assay. (A) Three 3'-UTR sequences containing normal, mutagenic, and deleted binding sites were inserted downstream of the luciferase reporter. Six nucleotides of IRS1 $3^{\prime}$-UTR were mutated or deleted to disrupt the binding with miR-146b seed regions. (B) Schematic diagram showing dual-luciferase reporter constructs of porcine IRS1 3'-UTR with putative miR-146b binding site; (C) Constructed vectors were transfected into Hela cells with miR-146 mimics or NC. The luciferase assay results revealed significant differences between miR-146b mimic and NC groups transfected with vectors containing normal IRS1 3'UTR $(n=8, * p<0.05)$.

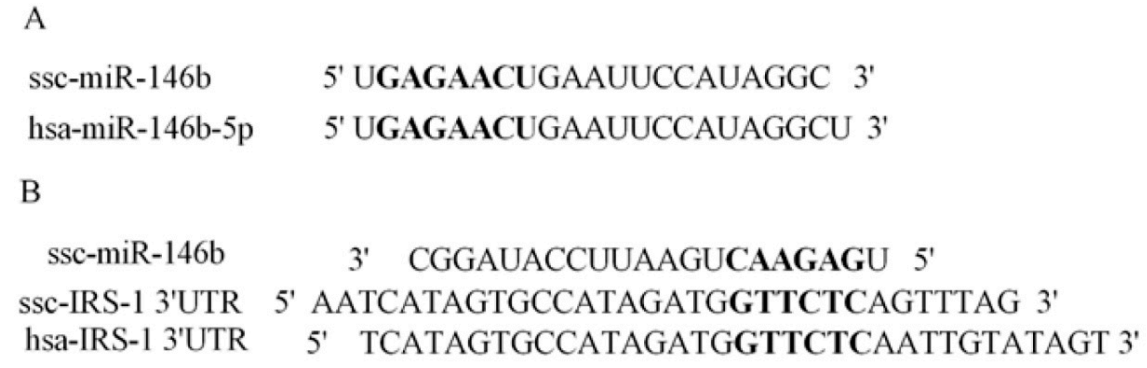

Figure 6. Conserved analysis of miR-146b and its target gene across species.(A) The bold letter showed that porcine miR-146b shared the same sequences of seed region with human miR-146b; (B) The bold pointed out that $3^{\prime} \mathrm{UTR}$ of human IRS1 mRNA is in accordance with ssc-miR-146b binding site.

\section{5. miR-146bend Base Mutation Changes miR-146b Targeting on IRS1 by Luciferase Reporter Assay}

Since miR-146a-5p and miR-146b share the same seed region (Figure 7A)and only few end base mutations exist, three miR-146 mutants were synthesized to test the contribution of the end base on determination of miR-146b targets(Figure 7A). A targeted relationship between miR-146a-5p and the 
IRS1 gene was not detected in this paper (Figure 7A,C). The three mutants were co-transfected with the wild-type (pGLO-IRS1-3'-UTR) plasmid into Hela cells. At $48 \mathrm{~h}$ post-transfection, the luciferase activity of the wild-type IRS1 reporter was significantly reduced by miR-146b mut 1 compared with the NC. The miR-146b mut2 group also elicited similar results but the extent of the reduction is less than the ssc-miR-146b mut1 (Figure 8). The results showed that mutant 1 and mutant 2 still targeted $3^{\prime}$-UTR of IRS1 while mutant 3 failed to target IRS1, which indicated that the 18th and 21st base of miR-146b play a significant role in ssc-miR-146b targeting IRS1.

$\mathbf{A}$

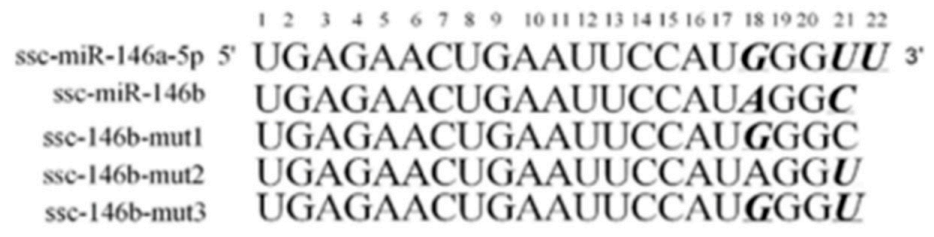

B
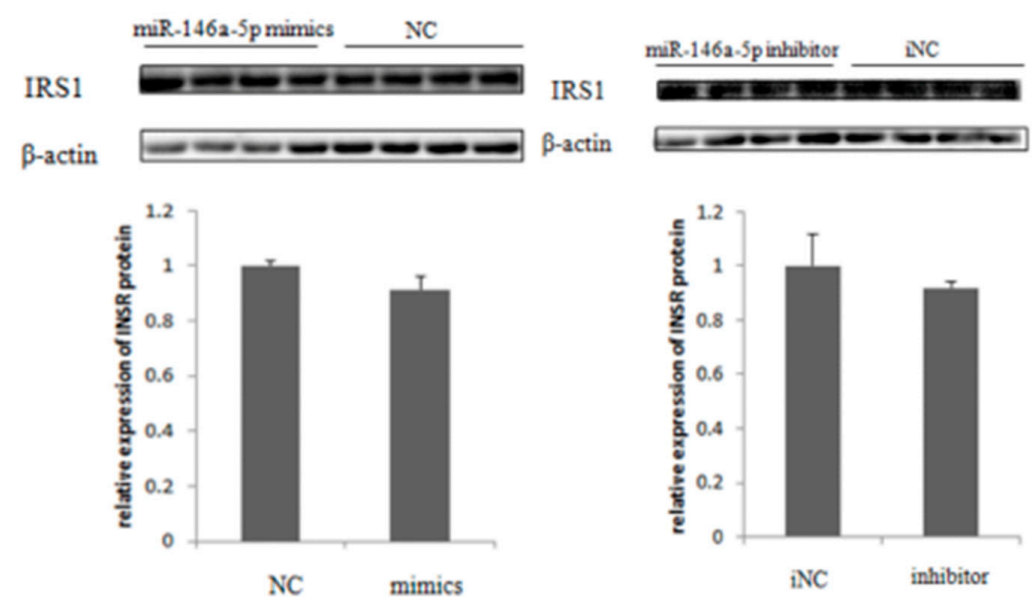

C

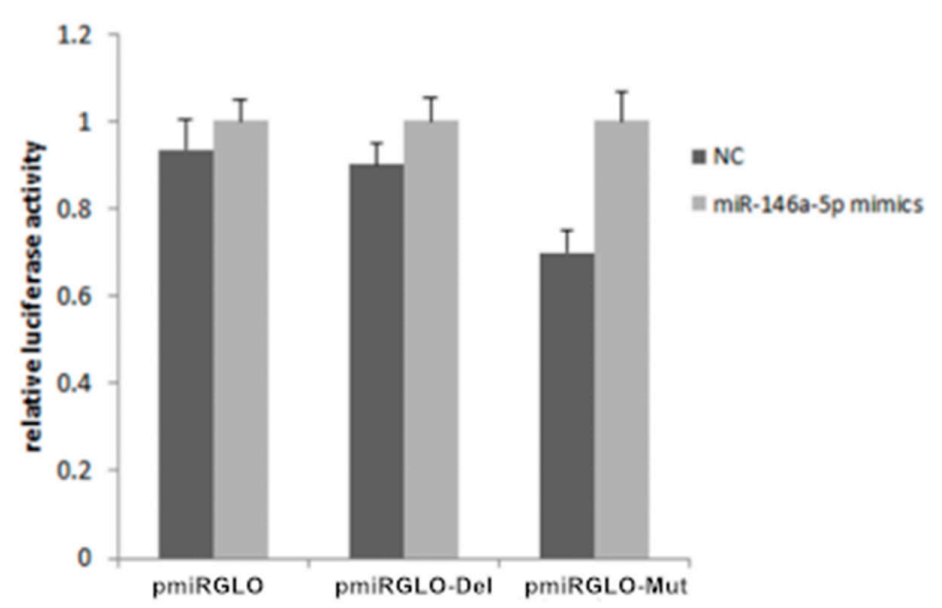

Figure 7. miR-146a-5p did not target IRS1 gene (A) miR-146a-5p is different from miR-146b at the 18th and the 21th base, and there is one more base at the end of miR-146a-5p. We therefore synthesized three mutants. For mut1, the 18th base A was replaced by G; for mut2, the 21 th base C was replaced by $\mathrm{U}$; for mut3, both the 18th and the 21th base were replaced according to the sequence the miR-146a-5p. (B) Western blot and gray-scale scanning analyses of IRS1 after transfection of miR-146a-5p mimics/NC/inhibitor/iNC $(n=4)$; (C) pmirGLO dual-luciferase reporter vectors analysis between miR-146a-5p and the $3^{\prime} \mathrm{UTR}$ sequences of IRS1 gene. 


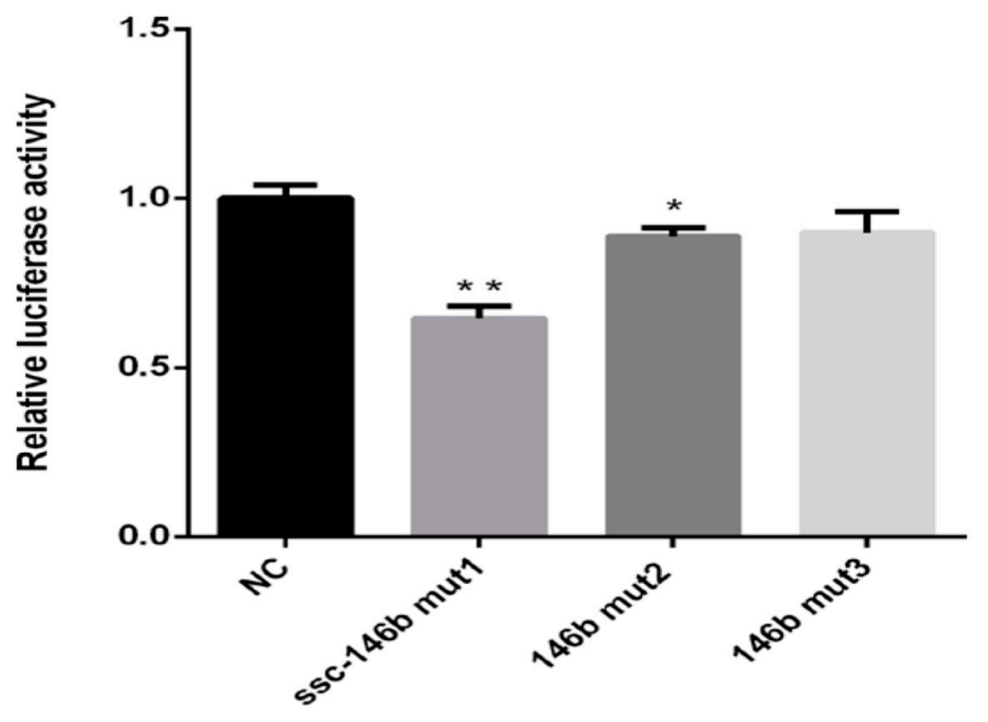

Figure 8. Analysis of end base mutation changes of miR-146b targeting on IRS1 by luciferasereporter assay $\left(n=8, * p<0.05,{ }^{* *} p<0.01\right)$.

\section{Discussion}

Adipose tissue mainly functions as a storage site for storing glucose and transforming into adipose. The profound effect of adipocytes on glucose balance is mediated by various mechanisms, which mostly performs in adipose tissue. Too much fat in the body exerts obesity and too little fat would exert lipodystrophy [8]. Obesity has become a worldwide problem, especially in Western countries. It can increase the risk of numerous diseases, particularly heart disease, type II diabetes, osteoarthritis and some types of cancer [50]. Thus, fully comprehending the mechanism of insulin signaling pathways and other biological processes in the adipose tissue is beneficial for exploring a potential target of obesity treatment.

Adipocytes uptake serum glucose to reserve energy as triglycerol and this process requires GLUT4 to transport the glucose from extracellular to intracellular locations [51,52]. GLUT4 is identified as the main glucose transporter in adipocytes $[12,13]$. After food consumption, glucose in the serum increases and GLUT4 is transported from an intracellular location in the adipocyte to the cell surface to uptake glucose for adipogenesis [53]. In the adipocyte, insulin signaling pathways control glucose transport via the IRS1/PI3K/GLUT4 signaling pathway. After insulin binds to IR, activated IR phosphorylates IRS1 [47]. Tyrosine-phosphorylated IRS1, recruits PI3K and later activates the GLUT4 translocation [48]. Therefore, reduced IRS1 expression could repress the GLUT4 translocation in adipocytes and also skeletal muscles, which results in the decrease of glucose uptake. Such phenomena always accompany insulin resistance and diabetes [10,54-57].

The miR-146 family of microRNAs consists of two members, miR-146a and miR-146b. These two miRNAs are located on different chromosomes and conduct different functions in the body. Additionally, many studies have illustrated that miR-146a and miR-146b target different genes in various cases. Studies of miR-146a and miR-146b mostly focus on inflammation [58-62] but the biological functions of the miR-146 family in adipose tissue remains largely unknown. In our previous study, the expression level of miR-146b was dramatically increased by 13.62-fold after TNF $\alpha$-induced adipogenesis according to a microarray assay analysis [47]. It is reasonable to suppose that miR-146b plays a vital role in adipocyte. Additionally, whether its target gene is identical to miR-146a-5p is worth exploring since miR-146b shares the same seed with miR-146a-5p.

In this study, we examined the glucose consumption of adipocytes on days 4,6 and 8 . The glucose consumption was decreased by miR-146b mimics, and it was rescued by a miR-146b inhibitor. GLUT4 total protein in adipocyte was also significantly reduced by miR-146b mimics, and it was also rescued 
by the inhibitor. Therefore, we speculated that the reduction of the glucose uptake capability of adipocytes was related to GLUT4. In addition, PM GLUT4 protein was also reduced by miR-146b mimics. Thus, we speculated that miR-146b inhibiting GLUT4 translocation would be the reason for the reduced glucose consumption caused by miR-146b. However, luciferase reporter assays showed that ssc-miR-146b did not directly target porcine GLUT4. We supposed there might be other molecules involved in this process.

To further validate the mechanism of miR-146b regulating adipocyte glucose consumption, we examined the protein level of IRS1, since IRS1 is significantly related to GLUT4 translocation via insulin signaling. We found that miR-146b mimics suppressed IRS1 protein expression significantly, while the inhibitor rescued this decrease. Then, we carried out a luciferase reporter assay and verified that miR-146 directly targeted IRS1. Thus, we confirmed that miR-146 represses adipocyte glucose uptake via the IRS1/GLUT4 pathway by targeting IRS1.

As for the pig miR-146 family, miR-146a-5p and miR-146b shared the same seed region while only the two nucleotides on the $3^{\prime}$ end of the mature strand are different. In our previous study, miR-146a-5p was proved to target insulin receptor (IR) and thus inhibited lipogenesis in porcine primary adipocytes [47]. In this paper, miR-146b inhibited glucose consumption by targeting IRS1 instead of IR. To determine why miR-146a-5p and miR-146b target different genes although they share the same seed region, we synthesized three mutants of miR-146b; the end base was replaced to be in accordance with the miR-146a-5p sequence. We found out that only when the 18th and 21st base of ssc-miR-146b were replaced, the target relationship between miR-146b and IRS1 would be lost according to the luciferase reporter assay. It is possible that the regulatory functions of miR-146a-5p and miR-146b would be decided by the sequence outside of the seed region. Because of the stabilization of the miRNA-mRNA complex, which is formed during miRNA exerting its biological function, regulatory functions could be more probably affected by the $3^{\prime}$ end and not sequences in the seed of the mature miRNA [63], which may explain the result that miR-146a-5p and miR-146b target different genes.

Therefore, our study is the first to illustrate that miR-146b regulates glucose homeostasis in porcine primary pre-adipocytes by targeting IRS1 and it could be a potential target of type II diabetes in the future.

\section{Materials and Methods}

\subsection{Ethics Statement}

All of the animal experiments were performed under the instructions of Guangdong Province on the Review of Welfare and Ethics of Laboratory Animals approved by the Guangdong Province Administration Office of Laboratory Animals (GPAOLA). All animal procedures were carried out with the guidelines of the protocol (SCAU-AEC-2010-0416) approved by the Animal Ethics Committee of South China Agricultural University.

\subsection{Sample Collection and Culture of Porcinepre-Adipocytes}

Subcutaneous fat tissues from a 7-day-old piglet was isolated aseptically and transferred to Dulbecco's modified essential medium-F12 nutrient mixture (GIBCO, New York, NY, USA). After removing the visible connective tissues, the adipose tissue was cut into small cubes of about $1 \mathrm{~mm}^{3}$, and the subcutaneous pre-adipocytes were obtained as described in our previous study [47]. Minced tissue was transferred into a Carlsberg's flask, digested in $0.2 \%$ type-II collagenase $(1 \mathrm{mg} / \mathrm{mL}$, GIBCO) for $2 \mathrm{~h}$ at $37^{\circ} \mathrm{C}$, and then filtered through a $150 \mu \mathrm{m}$ mesh. Cells in the filtrate were centrifuged at $500 \mathrm{~g}$ for $10 \mathrm{~min}$, and erythrocytes were lysed using erythrocyte lysis buffer $\left(0.154 \mathrm{MNH}_{4} \mathrm{Cl}, 10 \mathrm{mM}\right.$ $\mathrm{KHCO}_{3}$ and $0.1 \mathrm{mM}$ EDTA). After filtering through a $40 \mu \mathrm{m}$ mesh, cells were rinsed with F12 and centrifuged at $1500 \mathrm{~g}$ for $5 \mathrm{~min}$. The pre-adipocytes were collected and plated in growth medium. The pre-adipocytes were cultured in 6-well plates and induced to mature adipocytes with induction 
medium(10\% FBS, F12, $50 \mu \mathrm{M}$ oleic acid, 0.5 M Moctoic acid, $50 \mathrm{nM}$ insulin, $50 \mathrm{nM}$ dexamethasone, and these reagents were purchased from Sigma, Ronkonkoma, NY, USA).

\subsection{Target Prediction and Pathway Analysis}

The 3'-untranslated region (UTR) sequences of porcine transcripts in the whole genome were obtained from Ensembl genome browser 80 (sscorfa10.2, www.ensembl.org/Sus_scrofa/). Porcine miR-146b sequences were downloaded from miRBase release 21 (www.mirbase.org), and RNAhybrid software (BGI, Shenzhen, China) was used to analyze miRNA targets by using its own algorithm. Our prediction was restricted to a perfect match of the seed region (2-7 bases of the miRNA $5^{\prime}$ end; G:U matches were permitted), due to the importance of the seed sequence for miRNA-mRNA binding. In addition, the Database for Annotation, Visualization and Integrated Discovery (DAVID) v6.7 online service (http:/ / david.abcc.ncifcrf.gov/) was used for Gene Ontology (GO) and Kyoto Encyclopedia of Genes and Genomes (KEGG) pathway analysis based on the potential targets of miR-146b.

\subsection{Transfection of miR-146b Mimics and miR-146b Inhibitor}

miR-146b mimics, miR-146b inhibitors, negative control (NC and iNC) were acquired from Shanghai GenePharma Co. (Shanghai, China). Pre-adipocytes at $80-90 \%$ confluency were used for transfections, and miRNA mimics or inhibitors of 100 pmol was prepared in each well. NC and iNC were used as negative controls for the miR-146b mimics and miR-146b inhibitors, respectively. Transfection was performed using Lipofectamine 2000 (Invitrogen, Carlsbad, CA, USA). After 6 hours of the transfection, the cell culture medium was replaced with induced medium. On the 4 th, 6 th and 8th day of induction, the supernatants (mimics group, NC group, inhibitor group and iNC group) were collected to conduct the glucose consumption assays and the cells induced to 8th day were conducted for Western blot of GLUT4 and IRS1.

\subsection{RNA Extraction and Real-Time PCR for miR-146b}

Total RNA was extracted from differentiated adipocytes using TRIzol reagent (Invitrogen ${ }^{\mathrm{TM}}$, Carlsbad, CA, USA), and RNA quality was determined by the NanoDrop 2000(Thermo Fisher Scientific, MA, USA). Total RNA ( $2 \mu \mathrm{g})$ was reverse-transcribed using M-MLV reverse transcriptase (Promega, Madison, WI, USA) with a specific hairpin primer for miR-146b (5'-CTCAACTGGTGTCGT GGAGTCGGCAATTCAGTTGAGGCCTAT-3'). Real-time PCR was performed with Bio-Rad CFX-96 thermocycler (Bio-Rad, Hercules, CA, USA) using $2 \times$ SYBR Green PCR Master Mix (Promega, Madison, WI, USA) with a miRNA-specific forward primer (5'-CAGTGAGAACTGAATTCCATAGGC- $\left.3^{\prime}\right)$ and a universal reverse primer ( $5^{\prime}$-ATCCAGTGCGTGTCGTGGA- $\left.3^{\prime}\right)$. The PCR reaction $(20 \mu \mathrm{L})$ consisted of $2 \mu \mathrm{L}$ of cDNA, $1.5 \mu \mathrm{M}$ of each primer, $10 \mu \mathrm{L}$ of $2 \times$ SYBR Green PCR Master Mix and distilled water. The reactions were processed for $5 \mathrm{~min}$ at $95^{\circ} \mathrm{C}$, followed by 40 cycles of $15 \mathrm{~s}$ at $95^{\circ} \mathrm{C}, 15 \mathrm{~s}$ at $58^{\circ} \mathrm{C}$, and $40 \mathrm{~s}$ at $72{ }^{\circ} \mathrm{C}$. miRNA expression level was normalized to that of the internal control U6 (sense: TGCTTCGGCAGCACATATAC, antisense: TTCACGAATTTGCGTGTCAT) in each sample by the $2^{-\Delta \Delta C t}$ method. Statistical differences between treatment and control groups were determined using Student's $t$-test at $p<0.05$.

\subsection{Glucose Consumption Assay}

Glucose consumption measurement was performed on used medium samples. During the differentiation of porcine pre-adipocytes, the supernatant was collected on day 4,6 and 8 to $1.5 \mathrm{~mL}$ centrifuge tubes for testing. Glucose consumption was assayed using the Glucose Assay Kit (BioSino, Beijing, China)based on the glucose oxidase method [64]. Total protein detected by the bicinchoninic acid (BCA) assay (Thermo Fisher Scientific, Waltham, MA, USA) was used for normalization of glucose content. 


\subsection{Protein Extraction and Western Blot}

Total proteins were extracted using radio immunoprecipitation assay (RIPA) buffer with protease inhibitors (Boston Bio Products, Boston, MA, USA). Plasma membrane (PM) proteins were extracted using the Membrane Protein Extraction Kit (BestBio, Shanghai, China). Protein levels were quantified by the BCA protein assay. Total protein $(25 \mu \mathrm{g})$ was loaded onto a $10 \%$ SDS-PAGE gel, separated by electrophoresis and transferred onto a polyvinylidene difluoride (PVDF) membrane. Blots were blocked with $6 \%$ skim milk and incubated overnight at $4{ }^{\circ} \mathrm{C}$ with primary antibody against GLUT4 (Abcam, Cambridge, UK)and IRS1 (Proteintech Group, Chicago, IL, USA), followed by incubation with secondary antibody for $1 \mathrm{~h}$ at room temperature and measured with a Fluor Chem M (ProteinSimple, Santa Clara, CA, USA). Protein expression was normalized by detection of $\beta$-actin (Abcam, Cambridge, UK). Duplicate experiments were conducted for all primary adipocyte proteins. The data were analyzed by Image J software (National Institutes of Health, Bethesda, MD, USA) and expressed as fold-change relative to the control group after normalizing against $\beta$-actin. Statistical differences between treatment and control groups were determined using Student's $t$-test at $p<0.05$.

\subsection{Plasmid Construction}

The $3^{\prime}$-UTR sequences of porcine transcripts in the whole genome were obtained from NCBI (http:/ / www.ncbi.nlm.nih.gov/). The 3'-UTR of IRS1 (Accession No. NM_001244489.1) contains the highly conserved binding sites for the miR-146b. The $3^{\prime}$-UTR sequence was inserted into pmirGLO Vector (Promega) with $\mathrm{XhoI}$ and $\mathrm{XbaI}$ double digestion to construct recombinant Dual-Luciferase reporter vectors, named as pGLO-IRS1-3'-UTR, pGLO-IRS1-3'-UTR-mut and pGLO-IRS1-3UTR-del. Meanwhile, mutagenic and deleted IRS1 3-'UTR reporter vector swere constructed with seven exchanged nucleotides or a deleted target site via DNA synthesis (Sangon Biotech, Shanghai, China).

\subsection{Dual-Luciferase Reporter Assay}

Hela cells were seeded at density of $3 \times 10^{4}$ cells per well in 96-well plates. When the cells reached $60-70 \%$ confluency, wild-type (pGLO-IRS1-3'-UTR), mutant (pGLO-IRS1-3'-UTR-mut and pGLO-IRS1-3'-UTR-del) plasmids were co-transfected with miR-146b mimics or negative control (NC) into Hela cells. Lipofectamine 2000 (Invitrogen) was used for mediating the transfection. Cells were collected at $48 \mathrm{~h}$ post-transfection, and the luciferase assays were performed with the Dual-Luciferase reporter assay system (Promega). The luciferase activities were normalized by renilla activity. Statistical differences between treatment and control groups were determined using Student's $t$-test at $p<0.05$.

Acknowledgments: This research was supported by grants from the National Key Research and Development Program of China (2016YFD0500503), the Key Project of Transgenic Animal (2014ZX0800948B), Natural Science Foundation of China program (31472163).

Author Contributions: Yong-Liang Zhang, Qian-Yun Xi, Jia-Jie Sun conceived the experiments; Yan-Ling Zhu, Ting Chen, Jia-Li Xiong, Di Wu, Jun-Yi Luo designed and performed the experiments; Yong-Liang Zhang, Qian-Yun Xi, Jia-Jie Sun provided guidance for the experiments; Jia-Jie Sun and Yan-Ling Zhu prepared the manuscript; Jia-Jie Sun analyzed the miRNA data.

Conflicts of Interest: The authors declare no conflict of interest.

\section{References}

1. Fantuzzi, G. Adipose tissue, adipokines, and inflammation. J. Allergy Clin. Immunol. 2005, 115, 911-919. [CrossRef] [PubMed]

2. Bozaoglu, K.; Bolton, K.; McMillan, J.; Zimmet, P.; Jowett, J.; Collier, G.; Walder, K.; Segal, D. Chemerin is a novel adipokine associated with obesity and metabolic syndrome. Endocrinology 2007, 148, 4687-4694. [CrossRef] [PubMed]

3. Puigserver, P. A cold-inducible coactivator of nuclear receptors linked to adaptive thermogenesis. Cell 1998, 92, 829-839. [CrossRef] 
4. Chehab, F.F.; Mounzih, K.; Lu, R.; Lim, M.E. Early onset of reproductive function in normal female mice treated with leptin. Science 1997, 275, 88-90. [CrossRef] [PubMed]

5. Mokdad, A.H.; Ford, E.S.; Bowman, B.A.; Dietz, W.H.; Vinicor, F.; Bales, V.S.; Marks, J.S. Prevalence of obesity, diabetes, and obesity-related health risk factors, 2001. JAMA 2003, 289, 76-79. [CrossRef] [PubMed]

6. Herman, M.A.; Kahn, B.B. Glucose transport and sensing in the maintenance of glucose homeostasis and metabolic harmony. J. Clin. Investig. 2006, 116, 1767-1775. [CrossRef] [PubMed]

7. Tirone, T.A.; Brunicardi, F.C. Overview of Glucose Regulation. World J. Surg. 2001, 25, 461-467. [CrossRef] [PubMed]

8. Rosen, E.D.; Spiegelman, B.M. Adipocytes as regulators of energy balance and glucose homeostasis. Nature 2006, 444, 847-853. [CrossRef] [PubMed]

9. Lunney, J.K. Advances in Swine Biomedical Model Genomics. Pigs Poult. 2008, 3, 179-184. [CrossRef]

10. Saltiel, A.R.; Kahn, C.R. Insulin signalling and the regulation of glucose and lipid metabolism. Nature 2001, 414, 799-806. [CrossRef] [PubMed]

11. Kersten, S. Mechanisms of nutritional and hormonal regulation of lipogenesis. EMBO Rep. 2001, 2, $282-286$. [CrossRef] [PubMed]

12. Suzuki, K.; Kono, T. Evidence That Insulin Causes Translocation of Glucose Transport Activity to the Plasma Membrane from an Intracellular Storage Site. Proc. Natl. Acad. Sci. USA 1980, 77, 2542-2545. [CrossRef] [PubMed]

13. Wardzala, L.J.; Jeanrenaud, B. Potential mechanism of insulin action on glucose transport in the isolated rat diaphragm. Apparent translocation of intracellular transport units to the plasma membrane. J. Biol. Chem. 1981, 256, 7090-7093. [PubMed]

14. Shepherd, P.R.; Kahn, B.B. Glucose transporters and insulin action-Implications for insulin resistance and diabetes mellitus. N. Engl. J. Med. 1999, 341, 248-257. [CrossRef] [PubMed]

15. Stenbit, A.E.; Tsao, T.S.; Li, J.; Burcelin, R.; Geenen, D.L.; Factor, S.M.; Houseknecht, K.; Katz, E.B.; Charron, M.J. GLUT4 heterozygous knockout mice develop muscle insulin resistance and diabetes. Nat. Med. 1997, 3, 1096-1101. [CrossRef] [PubMed]

16. Brozinick, J.T., Jr.; McCoid, S.C.; Reynolds, T.H.; Nardone, N.A.; Hargrove, D.M.; Stevenson, R.W.; Cushman, S.W.; Gibbs, E.M. GLUT4 overexpression in $d b / d b$ mice dose-dependently ameliorates diabetes but is not a lifelong cure. Diabetes 2001, 50, 593-600. [CrossRef] [PubMed]

17. Berg, J.M.; Tymoczko, J.L.; Stryer, L. Biochemistry, 5th ed.; W H Freeman: New York, NY, USA, 2002.

18. Martin, S.; Tellam, J.; Livingstone, C.; Slot, J.W.; Gould, G.W.; James, D.E. The glucose transporter (GLUT-4) and vesicle-associated membrane protein-2 (VAMP-2) are segregated from recycling endosomes in insulin-sensitive cells. J. Cell Biol. 1996, 134, 625-635. [CrossRef] [PubMed]

19. Slot, J.W.; Geuze, H.J.; Gigengack, S.; Lienhard, G.E.; James, D.E. Immuno-localization of the insulin regulatable glucose transporter in brown adipose tissue of the rat. J. Cell Biol. 1991, 113, 123-135. [CrossRef] [PubMed]

20. Martin, S.; Millar, C.A.; Lyttle, C.T.; Meerloo, T.; Marsh, B.J.; Gould, G.W.; James, D.E. Effects of insulin on intracellular GLUT4 vesicles in adipocytes: Evidence for a secretory mode of regulation. J. Cell Sci. 2000, 113 Pt 19, 3427-3438. [PubMed]

21. Cheng, Z.; Tseng, Y.; White, M.F. Insulin signaling meets mitochondria in metabolism. Trends Endocrinol. Metab. 2010, 21, 589-598. [CrossRef] [PubMed]

22. Yip, M.F.; Ramm, G.; Larance, M.; Hoehn, K.L.; Wagner, M.C.; Guilhaus, M.; James, D.E. CaMKII-Mediated Phosphorylation of the Myosin Motor Myo1c Is Required for Insulin-Stimulated GLUT4 Translocation in Adipocytes. Cell Metab. 2008, 8, 384-398. [CrossRef] [PubMed]

23. Myers, M.G., Jr.; White, M.F. Insulin signal transduction and the IRS proteins. Annu. Rev. Pharmacol. 1996, 36, 615-658. [CrossRef] [PubMed]

24. Lee, J.; Pilch, P.F. The insulin receptor: Structure, function, and signaling. Am. J. Physiol. 1994, 266, C319-C334. [CrossRef] [PubMed]

25. Bandyopadhyay, G.; Sajan, M.P.; Kanoh, Y.; Standaert, M.L.; Quon, M.J.; Reed, B.C.; Dikic, I.; Farese, R.V. Glucose activates protein kinase C-zeta /lambda through proline-rich tyrosine kinase-2, extracellular signal-regulated kinase, and phospholipase D: A novel mechanism for activating glucose transporter translocation. J. Biol. Chem. 2001, 276, 35537-35545. [CrossRef] [PubMed] 
26. Whiteman, E.L.; Cho, H.; Birnbaum, M.J. Role of Akt/protein kinase B in metabolism. Trends Endocrinol. Metab. 2002, 13, 444-451. [CrossRef]

27. Blume-Jensen, P.; Hunter, T. Oncogenic kinase signalling. Nature 2001, 411, 355-365. [CrossRef] [PubMed]

28. Foran, P.G.; Fletcher, L.M.; Oatey, P.B.; Mohammed, N.; Dolly, J.O.; Tavaré, J.M. Protein kinase B stimulates the translocation of GLUT4 but not GLUT1 or transferrin receptors in 3T3-L1 adipocytes by a pathway involving SNAP-23, synaptobrevin-2, and/or cellubrevin. J. Biol. Chem. 1999, 274, 28087-28095. [CrossRef] [PubMed]

29. Hajduch, E.; Alessi, D.R.; Hemmings, B.A.; Hundal, H.S. Constitutive activation of protein kinase B alpha by membrane targeting promotes glucose and system A amino acid transport, protein synthesis, and inactivation of glycogen synthase kinase 3 in L6 muscle cells. Diabetes 1998, 47, 1006-1013. [CrossRef] [PubMed]

30. Hill, M.M.; Clark, S.F.; Tucker, D.F.; Birnbaum, M.J.; James, D.E.; Macaulay, S.L. A Role for Protein Kinase B $\beta /$ Akt2 in Insulin-Stimulated GLUT4 Translocation in Adipocytes. Mol. Cell. Biol. 1999, 19, 7771-7781. [CrossRef] [PubMed]

31. Calin, G.A.; Croce, C.M. MicroRNA signatures in human cancers. Nat. Rev. Cancer 2006, 6, 857-866. [CrossRef] [PubMed]

32. Romao, J.M.; Jin, W.; Dodson, M.V.; Hausman, G.J.; Moore, S.S.; Guan, L.L. MicroRNA regulation in mammalian adipogenesis. Exp. Biol. Med. 2011, 236, 997-1004. [CrossRef] [PubMed]

33. Kim, H.S.; Lee, K.S.; Bae, H.J.; Eun, J.W.; Shen, Q.; Park, S.J.; Shin, W.C.; Yang, H.D.; Park, M.; Park, W.S.; et al. MicroRNA-31 functions as a tumor suppressor by regulating cell cycle and epithelial-mesenchymal transition regulatory proteins in liver cancer. Oncotarget 2015, 6, 8089-8102. [CrossRef] [PubMed]

34. Kohjima, M.; Higuchi, N.; Kato, M.; Kotoh, K.; Yoshimoto, T.; Fujino, T.; Yada, M.; Yada, R.; Harada, N.; Enjoji, M.; et al. SREBP-1c, regulated by the insulin and AMPK signaling pathways, plays a role in nonalcoholic fatty liver disease. Int. J. Mol. Med. 2008, 21, 507-511. [CrossRef] [PubMed]

35. Siddle, K. Signalling by insulin and IGF receptors: Supporting acts and new players. J. Mol. Endocrinol. 2011, 47, R1-R10. [CrossRef] [PubMed]

36. Alexander, R.; Lodish, H.; Sun, L. MicroRNAs in adipogenesis and as therapeutic targets for obesity. Expert Opin. Ther. Targets 2011, 15, 623-636. [CrossRef] [PubMed]

37. Esau, C.; Kang, X.; Peralta, E.; Hanson, E.; Marcusson, E.G.; Ravichandran, L.V.; Sun, Y.; Koo, S.; Perera, R.J.; Jain, R.; Dean, N.M.; et al. MicroRNA-143 regulates adipocyte differentiation. J. Biol. Chem. 2004, 279, 52361-52365. [CrossRef] [PubMed]

38. Esau, C.; Davis, S.; Murray, S.F.; Yu, X.X.; Pandey, S.K.; Pear, M.; Watts, L.; Booten, S.L.; Graham, M.; McKay, R.; et al. miR-122 regulation of lipid metabolism revealed by in vivo antisense targeting. Cell Metab. 2006, 3, 87-98. [CrossRef] [PubMed]

39. Rayner, K.J.; Sheedy, F.J.; Esau, C.C.; Hussain, F.N.; Temel, R.E.; Parathath, S.; van Gils, J.M.; Rayner, A.J.; Chang, A.N.; Suarez, Y.; et al. Antagonism of miR-33 in Mice Promotes Reverse Cholesterol Transport and Regression of Atherosclerosis. J. Clin. Investig. 2011, 121, 2921-2931. [CrossRef] [PubMed]

40. He, A.; Zhu, L.; Gupta, N.; Chang, Y.; Fang, F. Overexpression of micro ribonucleic acid 29, highly up-regulated in diabetic rats, leads to insulin resistance in 3T3-L1 adipocytes. Mol. Endocrinol. 2007, 21, 2785-2794. [CrossRef] [PubMed]

41. Leavens, K.F.; Birnbaum, M.J. Insulin signaling to hepatic lipid metabolism in health and disease. Crit. Rev. Biochem. Mol. Biol. 2011, 46, 200-215. [CrossRef] [PubMed]

42. Nandi, A.; Kitamura, Y.; Kahn, C.R.; Accili, D. Mouse models of insulin resistance. Physiol. Rev. 2004, 84, 623-647. [CrossRef] [PubMed]

43. Bushati, N.; Cohen, S.M. MicroRNA functions. Annu. Rev. Cell Dev. Biol. 2007, 23, 175-205. [CrossRef] [PubMed]

44. Karolina, D.S.; Armugam, A.; Tavintharan, S.; Wong, M.T.; Lim, S.C.; Sum, C.F.; Jeyaseelan, K. Correction: MicroRNA 144 Impairs Insulin Signaling by Inhibiting the Expression of Insulin Receptor Substrate 1 in Type 2 Diabetes Mellitus. PLoS ONE 2011, 6, e22839. [CrossRef]

45. Yu, Y.; Li, X.; Liu, L.; Chai, J.; Haijun, Z.; Chu, W.; Yin, H.; Ma, L.; Duan, H.; Xiao, M. miR-628 Promotes Burn-Induced Skeletal Muscle Atrophy via Targeting IRS1. Int. J. Biol. Sci. 2016, 12, 1213-1224. [CrossRef] [PubMed] 
46. Gaudet, A.D.; Fonken, L.K.; Gushchina, L.V.; Aubrecht, T.G.; Maurya, S.K.; Periasamy, M.; Nelson, R.J.; Popovich, P.G. miR-155 Deletion in Female Mice Prevents Diet-Induced Obesity. Sci. Rep. 2016, 6. [CrossRef] [PubMed]

47. Wu, D.; Xi, Q.Y.; Cheng, X.; Dong, T.; Zhu, X.T.; Shu, G.; Wang, L.N.; Jiang, Q.Y.; Zhang, Y.L. miR-146a-5p inhibits TNF- $\alpha$-induced adipogenesis via targeting insulin receptor in primary porcine adipocytes. J. Lipid Res. 2016, 57, 1360-1372. [CrossRef] [PubMed]

48. Bryant, N.J.; Govers, R.; James, D.E. Regulated transport of the glucose transporter GLUT4. Nat. Rev. Mol. Cell Biol. 2002, 3, 267-277. [CrossRef] [PubMed]

49. Kanzaki, M. Insulin receptor signals regulating GLUT4 translocation and actin dynamics. Endocr. J. 2006, 53, 267-293. [CrossRef] [PubMed]

50. Haslam, D.W.; James, W.P. Obesity. Lancet 2005, 366, 1197-1209. [CrossRef]

51. Cornelius, P.; MacDougald, O.A.; Lane, M.D. Regulation of adipocyte development. Annu. Rev. Nutr. 1994, 14, 99-129. [CrossRef] [PubMed]

52. James, D.E.; Brown, R.; Navarro, J.; Pilch, P.F. Insulin-regulatable tissues express a unique insulin-sensitive glucose transport protein. Nature 1988, 333, 183-185. [CrossRef] [PubMed]

53. Brady, M.J.; Nairn, A.C.; Saltiel, A.R. The regulation of glycogen synthase by protein phosphatase 1 in 3T3-L1 adipocytes. Evidence for a potential role for DARPP-32 in insulin action. J. Biol. Chem. 1997, 272, 29698-29703. [CrossRef] [PubMed]

54. White, M.F. IRS proteins and the common path to diabetes. AJP Endocrinol. Metab. 2002, 283, E413-E422. [CrossRef] [PubMed]

55. Sesti, G.; Federici, M.; Hribal, M.L.; Lauro, D.; Sbraccia, P.; Lauro, R. Defects of the insulin receptor substrate (IRS) system in human metabolic disorders. FASEB J. 2001, 15, 2099-2111. [CrossRef] [PubMed]

56. Smith, U. Impaired ('diabetic') insulin signaling and action occur in fat cells long before glucose intolerance-Is insulin resistance initiated in the adipose tissue? Int. J. Obes. Relat. Metab. Disord. 2002, 26, 897-904. [CrossRef] [PubMed]

57. Tanti, J.F.; Grémeaux, T.; van Obberghen, E.; Le Marchand-Brustel, Y. Serine/threonine phosphorylation of insulin receptor substrate 1 modulates insulin receptor signaling. J. Biol. Chem. 1994, 269, 6051-6057. [PubMed]

58. Chassin, C.; Kocur, M.; Pott, J.; Duerr, C.U.; Gütle, D.; Lotz, M.; Hornef, M.W. miR-146a mediates protective innate immune tolerance in the neonate intestine. Cell Host Microbe 2010, 8, 358-368. [CrossRef] [PubMed]

59. Curtale, G.; Mirolo, M.; Renzi, T.A.; Rossato, M.; Bazzoni, F.; Locati, M. Negative regulation of Toll-like receptor 4 signaling by IL-10-dependent microRNA-146b. Proc. Natl. Acad. Sci. USA 2013, 110, 11499-11504. [CrossRef] [PubMed]

60. Hou, J.; Wang, P.; Lin, L.; Liu, X.; Ma, F.; An, H.; Wang, Z.; Cao, X. MicroRNA-146a feedback inhibits RIG-I-dependent Type I IFN production in macrophages by targeting TRAF6, IRAK1, and IRAK2. J. Immunol. 2009, 183, 2150-2158. [CrossRef] [PubMed]

61. Sheedy, F.J.; O'Neill, L.A. Adding fuel to fire: MicroRNAs as a new class of mediators of inflammation. Ann. Rheum. Dis. 2008, 67, iii50-iii55. [CrossRef] [PubMed]

62. Xiang, M.; Birkbak, N.J.; Vafaizadeh, V.; Walker, S.R.; Yeh, J.E.; Liu, S.; Kroll, Y.; Boldin, M.; Taganov, K.; Groner, B.; et al. STAT3 induction of miR-146b forms a feedback loop to inhibit the NF- $\mathrm{kB}$ to IL-6 signaling axis and STAT3-driven cancer phenotypes. Sci. Signal. 2014, 7. [CrossRef] [PubMed]

63. Paterson, M.R.; Kriegel, A.J. miR-146a/b: A Family with Shared Seeds and Different Roots. Physiol. Genom. 2017, 49, 243-252. [CrossRef] [PubMed]

64. Trinder, P. Determination of blood glucose using an oxidase-peroxidase system with a non-carcinogenic chromogen. J. Clin. Pathol. 1969, 22, 158-161. [CrossRef] [PubMed]

(C) 2018 by the authors. Licensee MDPI, Basel, Switzerland. This article is an open access article distributed under the terms and conditions of the Creative Commons Attribution (CC BY) license (http://creativecommons.org/licenses/by/4.0/). 